\title{
Re-visitando a latência: reflexões teórico-clínicas sobre os caminhos da sexualidade
}

\author{
Audrey Setton Lopes de Souza* \\ Departamento de Psicologia da Aprendizagem, do Desenvolvimento e da Personalidade, Instituto de Psicologia, \\ Universidade de São Paulo, São Paulo, SP, Brasil
}

Resumo: A proposta deste trabalho é revisitar o período do desenvolvimento psicossexual denominado por Freud de latência. Pretendemos demonstrar a partir de reflexões teórico-clínicas que, longe de ser um momento de parada caracterizado pela ausência da sexualidade, este é um momento-chave para a organização psíquica do adolescente e do adulto, que exige um grande trabalho psíquico e que leva a grandes conquistas intelectuais, a um reordenamento da personalidade e a uma abertura para o mundo. Pretendemos também apontar como dificuldades na vivência desta fase de desenvolvimento aparecem em manifestações clínicas.

Palavras-chave: latência, desenvolvimento psicossexual, clínica psicanalítica, estágios de desenvolvimento.

A proposta freudiana de investigar o desenvolvimento da sexualidade infantil revolucionou a concepção sobre a infância e permitiu uma melhor compreensão do mecanismo de formação de sintomas. A partir desta concepção foi possível entender os modos como os adultos se organizam a fim de dar conta da tarefa de, por um lado, satisfazer seus desejos e, por outro, encontrar formas de desviá-los ou controlá-los, como meio de sair do âmbito exclusivo da vida familiar e incluir-se na vida social, permitindo também utilizar criativamente seus recursos no desenvolvimento da civilização.

Muito aprendemos sobre o complexo de Édipo, a adolescência e as aquisições da primeira infância; no entanto, pouca atenção tem sido dedicada ao período denominado período de latência.

Referindo-se ao desenvolvimento da sexualidade, Freud (1905/1980a) destaca que ele ocorre em duas fases, sendo interrompido pelo período de latência. $\mathrm{O}$ autor dedica uma atenção especial a este período, que seria uma das condições necessárias para a aptidão dos homens de desenvolver uma civilização superior - mas também para sua tendência à neurose. Segundo ele:

Durante este período, a produção de excitação sexual não é de forma alguma interrompida, pois continua e produz uma reserva de energia que se utiliza em grande parte para finalidades não sexuais - ou seja, por um lado, contribuir com os componentes sexuais para os sentimentos sociais e, por outro (através da repressão e da formação reativa), construir as barreiras subsequentemente desenvolvidas contra a sexualidade. (p. 239)
Pretendemos neste artigo realizar um estudo mais detalhado deste período a fim de marcar a importância das aquisições que nele são alcançadas, pois, longe de ser uma parada no desenvolvimento, a latência é um momento que exige um grande trabalho psíquico e que leva a grandes conquistas intelectuais, a um de reordenamento da personalidade e a uma abertura para o mundo. Ela pode ser considerada como um momento-chave para a organização psíquica e o desenvolvimento emocional; devemos, portanto, compreendê-la para além do seu encobrimento manifesto, pois "a fase de latência se caracteriza mais pela estreiteza do ângulo de visão do psicanalista do que pela pobreza da fantasmatização da criança" (Diatkine, citado por Urribarri, 2012, p. 290).

A maneira como a criança pequena consegue afastar-se da relação exclusiva com seus pais, reorganizar sua sexualidade abandonando temporariamente as urgências edípicas, dirigir seu interesse para fins não sexuais e desenvolver as aquisições típicas da latência fornecerá as bases para o enfrentamento e a instalação dos processos da puberdade e da adolescência.

Se puder se consolidar uma relação intersistêmica fluida, que possibilite a descarga por via da sublimação (e a ocorrência de outros mecanismos), e não centrada na formação reativa e na repressão (que constringe, enrijece e empobrece pelo desgaste da contracatexia), se produzirá a ampliação e fortalecimento do ego, particularmente na diversificação de canais de expressão e descarga, ligações relacionais e institucionais, ampliação do pensamento e da linguagem, e fundamentalmente na articulação e funcionalidade do pré-consciente. Quanto menos embasada se encontra a organização prévia, menos

* Endereço eletrônico: asetton@uol.com.br 
recursos o jovem terá para enfrentar o embate puberal. (Urribarri, 2012, p. 141)

Se para o observador desatento o latente parece empobrecido quando comparado à riqueza imaginativa e à espontaneidade da criança pequena, perceber o que se opera internamente neste período dará a dimensão da revolução e do crescimento que ocorre no silêncio da latência.

Isto nos permite vislumbrar a hipótese de que, no empobrecimento da vida imaginativa encontrado em grande parte dos adultos na sociedade atual - cujo modelo predominante de inserção social é um padrão de ausência de questionamento, uma massificação das atitudes e uma diminuição brutal do círculo de relacionamentos interpessoais, com relacionamentos cada vez menos criativos e espontâneos -, possamos estar diante de aparentes latentes travestidos de adultos.

Refiro-me àqueles adultos excessivamente conformados e adaptados socialmente, que apresentam uma submissão aos valores do grupo sem pelo visto questionar-se, pessoas empobrecidas do ponto de vista individual. Parecem imitar serem pessoas adultas, mas, em nossa hipótese, teriam desistido da luta típica do latente: a luta de uma personalidade lutando por ser - perdendo a chance de operar a sua latência, momento no qual ocorre o embate entre quem a pessoa é e todo o terror e triunfo superegoico que poderá levar à pura imitação dos modelos parentais.

Este é o perigo que observo em alguns latentes que atualmente chegam a nossas clínicas. Receosos de afastarse dos modelos parentais e aproximar-se de seus pares, oprimidos por excessivas exigências superegoicas, parecem temer crescer e diferenciar-se.

Ao refletir sobre a clínica psicanalítica com crianças na atualidade, observo que, se antes atendíamos, mais frequentemente, crianças próximas do modelo do pequeno Hans (Freud, 1909/1980b), com queixas de dificuldades na escola - quer fossem de aprendizagem, quer de comportamento -, ruidosas, briguentas e abertamente competitivas, nas quais a rivalidade edípica parecia evidente e que deixavam a sala e o terapeuta aos frangalhos após atendê-las, hoje recebemos, com regularidade, meninos e meninas mais velhos, entre 8 e 10 anos, bons alunos, altamente críticos consigo mesmo e sem problemas de aprendizagem; não dão trabalho na escola - apenas sofrem nas viagens com a escola, temem ficar longe de seus pais ou têm poucos amigos. Quanto aos sintomas, predominam traços obsessivos e queixas de somatizações. Atendê-los também nos deixa exaustos, não tanto pela bagunça, mas pela falta dela; às vezes, nos percebemos mais infantis durante as brincadeiras do que os pequenos pacientes - é o analista quem vibra com a vitória, reclama da derrota ou tem vontade de trapacear, uma forma encontrada para sobreviver à aridez destes encontros; surpreendentemente, estes pacientes parecem beneficiar-se muito desta situação - pequenos adultos atendidos por um psicanalista criança. Desculpem o aparente exagero desta exposição quase caricatural, mas acredito que ela permita apresentar certo tipo de criança que solicita nossa atenção na clínica.

Como exemplo desta configuração, lembro-me de um menino que chegou até mim aos 9 anos de idade: ótimo aluno, extremamente inteligente, de uma família afetiva e preocupada, que veio em busca de uma psicoterapia para seu filho após um surpreendente relato da escola: ao se pedir à criança um desenho sobre sua experiência naquele semestre, o resultado foi um círculo vazio. Como queixa dos pais, apenas uma dificuldade do filho para evacuar e o receio de ir aos passeios da escola. Comecei a atender "um leguista" e "construtor de labirintos" ao término da análise, tive notícias de que os bichinhos de pelúcia haviam saído do armário para participar de uma intensa brincadeira em uma cidade imaginária, repleta de amigos e inimigos, que o irmão menor também adorava compartilhar: o buraco vazio parecia estar mais preenchido.

Recebo também doces meninas, grudadas a suas mães, mas com dores de cabeça, enjoos e medo de dormir sozinhas e que, após a análise, podem expressar mais abertamente suas rivalidades edípicas e, eventualmente, brigar um pouco com suas mães, bem como descobrir que têm pais e que podem aproximar-se deles.

Para dar conta destas observações clínicas, este artigo se propõe a re-visitar o trabalho psíquico da latência.

Faz parte da experiência de qualquer analista o conhecimento de que atender latentes implica estar disponível para infindáveis sessões de jogos, cheios de rigorosas regras que traduzem a rigidez das defesas presentes nesta etapa do desenvolvimento. Mas por que tantos latentes chegam hoje aos consultórios? Sendo o jogo o mesmo, por que eles não estão dando conta de manter latente o que os fazia latentes?

A questão "O que é latente no latente?" é formulada em interessante artigo do casal Sandler e Ligia Mattos. Seu trabalho aponta que o que é latente no latente é a turbulência emocional (Sandler, Mattos, \& Sandler, 2000), uma forma de se preparar em silêncio por meio de um incremento do elemento racional e da ênfase na realidade objetiva. A repressão da sexualidade estaria a serviço do enquadramento do indivíduo na psicologia do grupo - um período importante para a criança sair do pequeno grupo da família e tornar-se membro da espécie. Eles destacam que, no latente, a elaboração psíquica pode estar camuflada, acontecendo em surdina, sem muitas evidências, perspectiva que aponta o modo de operar do latente: na surdina. Assim, em vez de pensá-lo pelo que ele parece não ter (imaginação, insight), devemos considerá-lo como algo que se opera poderosamente no silêncio.

Sabemos, a partir de Freud, que o que fica latente na latência são a sexualidade e o complexo de Édipo, mas nos interessa destacar também o trabalho psíquico que se opera neste período.

Freud, ao debruçar-se sobre o desenvolvimento da sexualidade infantil, denomina de latência o período posterior ao complexo edípico e anterior às manifestações da puberdade, e que tem como marca um aparente apagamento da sexualidade. Ele soube ver por detrás desta ausência 
um período responsável pela construção, no aparelho psíquico, das barreiras que contêm a sexualidade infantil, perversa polimorfa, e que permitem a introdução na cultura e na civilização.

Inicialmente, em "Três ensaios para uma teoria sexual" (Freud, 1905/1980a), ele aponta que, neste período de latência, poderes anímicos se opõem ao instinto sexual, canalizando-o e marcando seu curso, como diques que dirigem a sexualidade para o caminho das sublimações. Neste processo, a educação e aspectos herdados organicamente se combinam na tarefa de auxiliar a erigir estes diques, que a princípio aparecem como formações reativas. São os diques da sexualidade a repugnância, a vergonha e a moralidade, formações reativas que defendem a criança dos perigos da sexualidade agora proibida.

Para além das proibições, estes diques desviam o interesse exclusivo da criança por seu próprio corpo e pelo corpo de seus pais e o dirigem para o caminho da exploração do conhecimento e do mundo fora de casa, campo no qual a sublimação dos desejos sexuais permite o uso do pensamento como forma de aproximação, em oposição à fantasia ou à descarga imediata pela ação. Este tema será retomado com mais profundidade por Freud (1911/1980c) em "Formulações sobre os dois princípios do funcionamento mental", no qual a oposição entre princípio do prazer e princípio da realidade vai marcar a importância do pensamento, do brincar e do fantasiar.

Em artigos posteriores (Freud, 1923/1980d, 1924/1980e, 1926/1980f), a relação entre o período de latência e o complexo de Édipo é estabelecida com mais clareza. Estes artigos articulam teoricamente a repressão da sexualidade na latência como um subproduto do complexo edípico.

Neste momento, o investimento libidinal antes dirigido aos pais, objetos de amor e ódio, é substituído pelas identificações, dando origem ao superego e seu papel no controle instintual.

Desse modo, no início da latência, a criança volta as costas para o complexo de Édipo, processo que Freud (1924/1980e) descreve assim:

As catexias de objeto são abandonadas e substituídas por identificações. A autoridade do pai ou dos pais é introjetada no ego e aí forma o núcleo do superego, que assume a severidade do pai e perpetua a proibição deste contra o incesto, defendendo assim o ego contra o retorno da catexia libidinal. As tendências libidinais pertencentes ao complexo de Édipo são em parte dessexualizadas e sublimadas (coisa que provavelmente acontece com toda transformação em uma identificação) e em parte são inibidas em seu objetivo e transformadas em impulsos de afeição. . . . Esse processo introduz o período da latência, que agora interrompe o desenvolvimento sexual da criança. (p. 221)
Compreendemos agora por que a criança precisa afastar-se um pouco de seus pais, construir novos interesses e dirigir-se para outros objetos do mundo ao seu redor.

A mudança de comportamento que se observa na passagem da infância para a latência é facilmente percebida por aqueles que a acompanham, mas de difícil compreensão se não consideramos as modificações internas que estão se processando.

Lembro-me do encontro com um menino que não via há muito tempo; dirijo-me à criança da minha memória para beijá-la no rosto, como costumava fazer, mas me deparo com uma expressão de terror que alerta para o perigo desta terrível invasão que eu ousara tentar; resolvo estender-lhe a mão, percebendo que ele estava diferente $\mathrm{e}$ defrontando-se com a construção destas barreiras.

Neste momento, não encontramos mais aquelas crianças tão desinibidas e curiosas em relação aos mistérios da sexualidade, das diferenças sexuais, dos nascimentos dos bebês etc.; está em ação uma batalha interna que resulta na aparente extinção da curiosidade sexual, substituída agora por uma maior exigência de ordem e obediência.

Assim, a latência se apresenta como um período que se caracteriza por um encobrimento. Mas onde estará a sexualidade banida?

Vemos estas crianças que não podem mais beijarnos com tranquilidade; os grupos se dividem: meninos de um lado, meninas do outro; as roupas são mais largas e banem-se os vestidinhos enfeitados; estão tomadas as medidas para evitar os perigos da invasão da sexualidade.

Cheguemos mais perto para observar sobre o que falam entre si. Quantas piadas "sujas", às vezes só engraçadas por terem sujeiras (xixi, cocô, pinto etc.), podem ser contadas entre eles, longe do adulto! É entre eles que brincam saber de uma sexualidade que não sabem direito o que é. Mas, além das piadas, há o desconforto, a evitação do contato físico, a separação entre meninos e meninas - o perigo da curiosidade entre eles. Esqueçam-se daqueles que um dia brincaram de ser namorados do papai e da mamãe.

Referindo-se aos latentes, Klein (1932/1975) destaca a dificuldade encontrada pelos analistas para se aproximar da vida imaginativa destes pacientes e da atitude geral de reserva e desconfiança, tão típica deste período.

Esta atitude é, em parte, produto da intensa luta [em] que [estas crianças] se acham empenhadas contra a masturbação, isso as torna profundamente avessas a tudo o que tenha ressaibos de investigação sexual ou esbarre nos impulsos que elas procuram conter com tanta dificuldade. (p. 93)

Como uma das poucas autoras que se dedicou a este tema, Klein enfatiza o papel da escola na forma como cada criança enfrenta este trabalho de desviar e sublimar suas energias libidinais. Ela se deteve em como estas sublimações influenciam o estudo de algumas disciplinas, chegando às vezes a inibir a aprendizagem. Assinala ainda 
o ofuscamento da vida de fantasia, a necessidade de aprovação e de mostrar-se bom menino, mas também aponta para a ampliação do mundo das relações.

Anna Freud (1936/2006), tratando deste período, ressalta as relações entre id, ego e superego. Para ela, haveria um declínio fisiologicamente condicionado na força das pulsões, associado a uma espécie de armistício na guerra defensiva do ego em sua tarefa de dominar as exigências pulsionais.

Ele tem agora tempo suficiente para dedicar-se a outras tarefas e adquire novos conteúdos, conhecimento e capacidades. Ao mesmo tempo, torna-se mais forte em relação ao mundo exterior e menos impotente e submisso, deixando de encarar o mundo como a entidade onipotente que lhe parecia antes. Cessa a dependência completa dos pais e a identificação começa ocupando o lugar do amor -objeto. (p. 103)

A autora também indica a importância, nesta fase, da função do superego como resultado da introjeção dos princípios familiares e escolares.

Winnicott (1958/1983) aborda a latência referindose às dificuldades encontradas na análise destes pacientes, chamando a atenção para o fato de que o objetivo desta fase seria a contenção bem-sucedida das exigências pulsionais, o que tornaria a proposta analítica de associação livre uma ameaça para a organização almejada por seu ego em formação. Apoiado nestes argumentos, justifica as dificuldades na análise de tais pacientes:

A normalidade é essencial no período de latência e a criança que não pode manter a normalidade nesta fase está clinicamente muito doente. A organização do ego carrega nela o impulso, tanto antes como depois é carregado parcialmente pelo impulso do id. (p. 112)

Não raro, a latência é referida como uma espécie de buraco negro, e por vezes, como analistas, nos perguntamos onde foi parar a vida mental ou, ainda, onde vão parar as interpretações que formulamos. Na verdade, este é um período de reordenamento psíquico, que promove grandes mudanças psicológicas e sociais; um período que exige um intenso trabalho interno, que possibilitará a abertura para novas identificações, novos desenvolvimentos intelectuais. Como destacam Sandler et al. (2000), no latente, a elaboração psíquica pode estar camuflada, acontecendo em surdina, sem muitas evidências.

Por que não pensar que este é o modo de operar do latente - em surdina? Assim, em vez de pensá-lo pelo que ele parece não ter (imaginação, insight), devemos considerar algo que se opera poderosamente no silêncio.

Esta é também a posição de Urribarri (2012) para quem, apesar de este período instalar-se a partir do sepultamento do complexo de Édipo, seria extremamente empobrecedor e reducionista caracterizá-lo apenas desta forma. $\mathrm{O}$ autor aponta que a latência tem sido mais definida pela negativa - o que deixa de ocorrer - do que pelo positivo; ele, por sua vez, destaca o que surge e o que se complexifica neste período, marcado por mudanças na organização e no funcionamento do aparelho psíquico e por novas formas de conduta e de relações sociais. Tal perspectiva o leva a caracterizar o que denomina $o$ trabalho da latência:

Junto com o que se destrói ou coarta está o que se constrói e possibilita; junto ao que obriga à renúncia, o que oferece e constrói novos prazeres e destinos; ao que se aliena e se priva se contrapõe o que se domina e o que se torna autônomo, que se expressa em atividades, aprendizagens, expansões, relações, complexificações diversas etc. tanto no intra como no intersubjetivo. (p. 94)

Assim, podemos caracterizar a latência como o tempo no qual é realizado um extenso trabalho de congregar diversos mecanismos para um fim sublimatório.

Muitas são as conquistas decorrentes deste trabalho (Enck, 2007; Uribarri, 2012):

- a possibilidade do enfrentamento edípico abre o caminho para as relações exogâmicas, fora do universo familiar;

- o deslocamento do interesse pelo corpo para um interesse pelos objetos e seus mecanismos, para os fenômenos naturais e suas leis, propicia um amplo desenvolvimento intelectual e do pensamento;

- o ego se fortalece, tornando-se mais capaz dos deslocamentos que permitem as sublimações;

- em termos de linguagem, o predomínio da ação é substituído pela verbalização como forma de resposta;

- os jogos se tornam, cada vez mais, a principal via de descarga, evitando a masturbação e a agressividade excessiva;

- os desenhos se tornam mais complexos e elaborados, revelando uma maior discriminação entre fantasia e realidade;

- expande-se a relação consigo mesmo e com o outro, apesar do aparecimento da vergonha decorrente da internalização das normas;

- ocorre uma maior discriminação entre o público e o privado.

Vemos, desta forma, a magnitude do trabalho psíquico que está presente no período da latência.

Referindo-se às contribuições de Sandler et al. (2000) acrescentam que a latência pode ser concebida como o apogeu do embate entre individual-ismo e o social-ismo. Para Bion a menção exclusiva da sexualidade, comumente encontrada nos textos freudianos, ignora o fato contundente de que o indivíduo tem um problema mais perigoso para 
resolver - a saber, o embate entre a necessidade de lutar por seu grupo e a necessidade de agir no interesse de sua própria sobrevivência; o conflito entre o que ele chama de social-ismo e individual-ismo.

A história da constituição psíquica é importante, pois há tanto o perigo de um sacrifício excessivo do individualismo como o de, por exemplo, uma inibição excessiva da vida de fantasia ou, ainda, de uma excessiva dependência da autoridade, o que interferiria no aprendizado do socialismo.

O processo de humanização, que inclui a inserção no grupo e a adaptação a ele, a aquisição dos conhecimentos e da cultura da espécie, tem na repressão, tão característica da fase de latência, o seu baluarte, mas é necessário um equilíbrio entre o indivíduo e o social para evitar a perda total do contato com a realidade psíquica.

Ferrari (1996, p. 52) chama a atenção para o fato de que, na latência, há uma espécie de acordo de cavalheiros entre a psiquicidade e a fisicidade, um acordo tácito com um mínimo de conflito. Como a calma que antecede a tempestade da adolescência, a latência é, para o autor, um período de informação, uma experiência que prepara para a formação do indivíduo.

O latente se vale da latência para preparar-se, mas não é um buraco; trata-se de um período de informação, tanto consciente quanto inconsciente, uma informação que assessora para a vivência da adolescência. Somente se estas informações forem bastante funcionais e numerosas, e se não encontrarem demasiados obstáculos, será possível dispor de um bom arsenal para enfrentar a adolescência. $\mathrm{O}$ objetivo seria alcançar uma capacidade de gerir o mundo de suas emoções, ocupar-se de si mesmo.

Seria como uma possibilidade de usar a mente com uma atividade orientada para a busca dos elementos fundamentais para encontrar uma identidade, num processo de diferenciação dos outros e do mundo, na construção da futura individuação.

Nesta fase, o jogo e a procura de conhecimento seriam uma tentativa de conhecer o outro e a si mesmo, suas atitudes, sua força física, seus gostos, suas tendências nas relações interpessoais etc. Trata-se de uma criança, agora taciturna, que busca estabelecer comparações, observar as diferenças; que compara seus pais com os pais de seus amigos, que estabelece as primeiras percepções das diferenças econômicas, estéticas e sociais. Trata-se de um processo de discriminação e diferenciação.

É uma fase para ser vivenciada - não muito cedo, para não se perder a infância, mas que não pode deixar de ser vivida.

Ferrari (1996) alerta que, se os analistas se frustram ao atender estas crianças, talvez seja porque procurem aí a inventividade infantil, e não o que é essencial neste período - esta dolorosa busca da individuação.

Por isso, podemos pensar que uma parte importante da elaboração edípica pode ser feita na latência: livre do desejo totalizador de posse do período edípico e com a diminuição pulsional, o latente percorre caminho fundamental na busca da sua identidade - saindo do espaço circunscrito da família, ele se abre para o mundo a fim de testar suas primeiras hipóteses e teorias infantis.

A maneira como se desenvolve o período de latência, visto sob este ângulo, será determinante para a forma como este jovem enfrentará a turbulência da puberdade e da adolescência.

Tentei fazer, neste artigo, algumas incursões por caminhos teóricos que nos permitissem notar como esta interrupção observada por Freud no desenvolvimento da sexualidade - que dividiria em duas fases o seu aparecimento - é muito mais do que um hiato ou um buraco vazio; é um "copo cheio de ar", um ar vital para o desenvolvimento da vida; é a possibilidade de o latente respirar este ar, conhecendo a si mesmo, preparando o terreno para a adolescência e oferecendo subsídios imprescindíveis para a construção da identidade.

Assim, o que parece ausente no latente, na verdade, está latejando no processo de uma personalidade em formação.

Tudo isto considerado, fica a questão de como o mundo em que vivemos interfere neste processo. Se for verdade que os latentes hoje não estão mais dando conta desta tarefa e chegam com mais frequência a nossas clínicas, do que se trataria?

Há um caminho mais imediato: as novas organizações familiares não estariam contribuindo para a elaboração do Édipo. Sei que é um caminho possível; acredito, porém, que há mais do que isto.

Ferrari (1996) diz que a latência é um momento de reflexão sobre o mundo; mas haverá espaço para isto em um mundo onde cada vez mais nos fechamos em guetos e há muita pouca chance de se conhecer o diferente? Como é possível a existência do diferente numa cultura tão massificada, em que o novo é engolido, mastigado e devorado tão rapidamente que logo já é mais um igual?

Em um mundo dominado pelas redes sociais, a existência individual parece coisa de outro planeta; a impressão é que não existem barreiras entre o eu e o outro. Onde começa o outro e seus limites parece um enigma neste universo, no qual é possível saber tudo sobre o outro sem precisar que ele me diga - posso encontrá-lo na hora em que eu quiser, pois não há mais distâncias em um mundo de internet, redes sociais e celulares.

Se o latente precisa sair do narcisismo e adentrar o social-ismo, o que é o social-ismo num mundo sem limites, um mundo que prega o narcisismo?

Como libertá-lo para tal processo se a sexualidade entra pelos sete buracos de sua cabeça? Sobra uma espécie de pavor se o sexual, do qual tenta se afastar, corre atrás dele para lhe invadir, e o conhecimento do mundo não lhe é oferecido.

Quanto às famílias, eu as tenho visto preocupadas em estar presentes ao lado de seus filhos - não sei se sempre realmente envolvidas ou se, às vezes, para cumprir certo modelo de presença. Tenho visto muitos casais que deixaram de ter uma vida própria - culpados, pois 
precisam estar com os filhos, conversar com eles, oferecerlhes o melhor. Quem sabe não seria útil acreditarem um pouco mais na capacidade de seus filhos de estar sós, cultivar suas amizades, aprender a aprender sobre o mundo.

Vejo que consigo ajudar as minhas crianças em análise quando lhes é permitido seguir suas investigações com mais liberdade; quando o caminho da rivalidade edípica não é mais tão apavorante, na medida em que seus pais também podem ter espaço para uma vida social e de casal; quando a diminuição da rigidez superegoica permite acreditar que o mundo fora da família não é só repleto de ladrões e sequestros; quando os amigos podem ser companheiros com os quais podem trocar descobertas, sem a intrusão dos pais.

Peço desculpas ao leitor se mais perguntei do que respondi. Sempre se aprende quando se pergunta. É verdade que sofremos; parece um percurso árduo, quase impossível de ser percorrido; mas, quando é possível seguir, cresce-se mais um pouco.

\section{Re-visiting the latency: Clinical and theoretical reflections about the ways of the sexuality}

Abstract: The purpose of this work is to revisit the psychosexual development period that Freud called latency. We intend to demonstrate based on clinical and theoretical reflections that, far from being a stop-time characterized by the absence of sexuality, this is a key moment for the teenager and adult psychological organization, which requires a great psychic work and leads to great intellectual achievements, a reordering of the personality and an openness to the world. We also intend to point out how the difficulties on the experience of this stage of development appear in clinical manifestations.

Keywords: latency, psychosexual development, psychoanalytic clinic, developmental estates.

\section{Revisiter la latence: réflexions cliniques et théoriques sur les chemins de la sexualité}

Résumé: Ce travail revisite la période du développement psychosexuel que Freud appelle la latence. À partir de réflexions cliniques et théoriques, nous cherchons à démontrer que, loin d'être un temps d'arrêt caractérisé par l'absence de sexualité, il s'agit d'un moment-clé pour l'organisation psychique des adolescents et des adultes. Il nécessite un grand travail psychique et il conduira à grandes réalisations intellectuelles, puisque c'est une réorganisation de la personnalité et une ouverture sur le monde. Nous soulignions aussi comment les difficultés à vivre ce moment du développement apparaissent comme des manifestations cliniques.

Mots-clés: latence, développement psychosexuel, clinique psychanalytique, états de développement.

\section{Re-visitando la latencia: reflexiones teóricas y clínicas sobre los caminos de la sexualidad}

Resumen: El propósito de este trabajo es revisitar el período de desarrollo psicosexual a que Freud llama latencia. Tenemos la intención de demostrar a partir de reflexiones teóricas y clínicas que, lejos de ser un tiempo de parada que se caracteriza por la ausencia de la sexualidad, este es un momento clave para la organización psíquica del adolescente y del adulto, que requiere un gran trabajo psíquico y que da lugar a grandes logros intelectuales, a un reordenamiento de la personalidad y a una apertura para el mundo. También tenemos la intención de señalar cómo las dificultades en la experiencia de esta etapa del desarrollo se expresan como manifestaciones clínicas.

Palabras clave: latencia, desarrollo psicosexual, clínica psicoanalítica, estados de desarrollo.

\section{Referências}

Enck, E. M. N. (2007). O encurtamento da latência e a puberdade precoce: um problema dos tempos atuais. Recuperado de http://febrapsi.org.br/publicacoes/artigos/xxi_cbp_eluza.doc

Ferrari, A. B. (1996). Adolescência: o segundo desafio considerações psicanalíticas (M. Mortara, trad). São Paulo, SP: Casa do Psicólogo.
Freud, A. (2006). O ego e os mecanismos de defesa (F. Settineri, trad.). Porto Alegre, RS: Artmed. (Trabalho original publicado em 1936)

Freud, S. (1980a). Três ensaios para uma teoria sexual. In S. Freud, Edição standard brasileira das obras psicológicas completas de Sigmund Freud (J. Salomão, 
trad., Vol. 7, pp. 123- 252). Rio de Janeiro, RJ: Imago. (Trabalho original publicado em 1905)

Freud, S. (1980b). Análise de uma fobia de um menino de cinco anos/Hans. In S. Freud, Edição standard brasileira das obras psicológicas completas de Sigmund Freud (J. Salomão, trad., Vol. 10, pp. 13-154). Rio de Janeiro, RJ: Imago. (Trabalho original publicado em 1909)

Freud, S. (1980c). Formulações sobre os dois princípios do funcionamento mental. In S. Freud, Edição standard brasileira das obras psicológicas completas de Sigmund Freud (J. Salomão, trad., Vol. 12, pp. 273-286). Rio de Janeiro, RJ: Imago. (Trabalho original publicado em 1911)

Freud, S. (1980d). O ego e o id. In S. Freud, Edição standard brasileira das obras psicológicas completas de Sigmund Freud (J. Salomão, trad., Vol. 19, pp. 13-83). Rio de Janeiro, RJ: Imago. (Trabalho original publicado em 1923)

Freud, S. (1980e). A dissolução do complexo de Édipo. In S. Freud, Edição standard brasileira das obras psicológicas completas de Sigmund Freud (J. Salomão, trad., Vol. 19, pp. 215-224). Rio de Janeiro, RJ: Imago. (Trabalho original publicado em 1924)

Freud, S. (1980f). Inibições, sintomas e ansiedade. In S. Freud, Edição standard brasileira das obras psicológicas completas de Sigmund Freud (J. Salomão, trad., Vol. 20, pp. 95-200). Rio de Janeiro, RJ: Imago. (Trabalho original publicado em 1926)

Klein, M. (1975). A técnica de análise no período de latência. In M. Klein, Psicanálise da criança (P. Civelli, trad., pp. 93-119). São Paulo: Mestre Jou. (Trabalho original publicado em 1932)

Sandler, E. H., Mattos, L. T. L., \& Sandler, P. C. (2000). Latência? Psychê, (6), 53-73.

Urribarri, R. (2012). Estruturação psíquica e subjetivação da criança em idade escolar: o trabalho da latência (E. R. Sang, trad.). São Paulo, SP: Escuta.

Winnicott, D. W. (1983). O ambiente e os processos de maturação: estudos sobre a teoria do desenvolvimento emocional (I. C. S. Ortiz, trad.). Porto Alegre, RS: Artes Médicas. (Trabalho original publicado em 1958)

Recebido: 02/08/2013

Revisado: 14/02/2014

Aceito: 10/04/2014 